\title{
KOMPATIBILITAS JAMUR ENTOMOPATOGENIK Paecilomyces fumosoroseus DENGAN BEBERAPA BAHAN AKTIF PESTISIDA SECARA IN VITRO
}

\section{COMPATIBILITY OF ENTOMOPATHOGENIC FUNGI Paecilomyces fumosoroseus WITH SOME ACTIVE AGENTS OF PESTICIDE IN VITRO}

\author{
Fani Fauziah dan Dadan Rohdiana \\ Pusat Penelitian Teh dan Kina Gambung \\ Desa Mekarsari, Kecamatan Pasirjambu 40972 \\ Korespondensi : fani_fauziah@ymail.com \\ Diterima 20 Juli 2016 / Disetujui 30 Oktober 2016
}

\begin{abstract}
ABSTRAK
Penggunaan pestisida di perkebunan teh dapat dikurangi dengan adanya kombinasikan aplikasi pestisida dengan jamur entomopatogenik. Penelitian ini bertujuan untuk mengetahui kompatibilitas antara jamur $P$. fumosoroseus dengan beberapa bahan aktif pestisida di laboratorium. Perlakuan dirancang dengan Rancangan Acak Lengkap (RAL) terdiri dari 5 jenis bahan aktif yaitu metomil, bifentrin, imidakloprid, tembaga oksida dan metidation pada taraf konsentrasi sesuai rekomendasi lapang (RL), $0,5 x$ RL dan $2 x$ RL. Hasil pengamatan menunjukkan bahwa diantara kelima jenis bahan aktif pestisida yang diuji, metidation memiliki tingkat toksisitas yang paling tinggi. Persentase produksi spora tertinggi sebesar $13,77 \%$ ditunjukkan oleh perlakuan bifentrin 2x RL.
\end{abstract}

Kata kunci : Jamur entomopatogenik, Kompatibilitas, Paecilomyces fumosoroseus, Pestisida

\begin{abstract}
Combining application of pesticides and entomopathogenic fungi is an alternative way for controlling pest in order to reduce pesticides application in the tea field. This research was aimed to examine the compatibility of Paecilomyces fumosoroseus to some active agents of pesticide in laboratory. Completely Randomized Block Designed (CRBD) with 5 active agents: methomyl, bifenthrin, imidacloprid, copper oxide and metidation in three different concentration was employed in this study, which was based on the existing field recommendation (FR): 0,5x FR and 2x FR. The results showed that among the five tested pesticides, metidation appeared to be the most toxic agent to $P$. fumosoroseus. Meanwhile, the highest percentage of spore production was counted in bifenthrin $2 \times \operatorname{RL}(13,77 \%$.)
\end{abstract}

Keywords : Compatibility, Entomopathogenic Fungi, Paecilomyces fumosoroseus, Pesticides

\author{
PENDAHULUAN \\ Insektisida kimia sintetik telah mem- \\ berikan banyak manfaat sekaligus kerugian
}

di bidang pertanian. Penggunaan pestisida yang tidak tepat dan berlebihan, dapat meningkatkan biaya produksi dan mengakibatkan pengaruh negatif terhadap ling- 
kungan, kesehatan, dan menimbulkan resistensi hama serta resurgensi (Ambethgar, 2009; Sunarno 2012). Adanya berbagai dampak negatif akibat peng-gunaan insektisida kimia sintetik tersebut telah mendorong terciptanya konsep pengendalian hama terpadu (PHT) yang mempergunakan dasar pertimbangan ekologi dan efisiensi dalam rangka pengelolaan agroekosistem yang ber-tanggung jawab dan lebih bijaksana untuk meminimalkan penggunaan pestisida (Ross et al., 1982). Upaya yang sekarang banyak dilakukan adalah mengkombinasikan pengendalian hama dengan agen hayati dan aplikasi pestisida sintetik (Lacey dan Goettel, 1995).

Salah satu agen hayati yang memegang peranan penting dalam menurunkan kepadatan populasi hama adalah jamur entomopatogenik. Hasil penelitian di Pusat Penelitian Teh dan Kina (PPTK) Gambung menunjukkan bahwa jamur entomopatogenik Paecilomyces fumosoroseus efektif terhadap ulat api (Setora nitens), dan 4 spesies ulat jengkal (Ectropis bhurmitra, Boarmia bhurmitra, Antitry-godes divisaria dan Hyposidra talaca) dengan tingkat kematian maksimal mencapai $75-100 \%$. Sementara itu, hasil pengujian lapangan menunjukan $P$. fumosoroseus dapat menurunkan inten-sitas serangan ulat jengkal bahwa pada tanaman teh sampai dengan $60 \%$ dan efektivitasnya setara dengan insektisida kimia pembanding yaitu monokrotopos pada dosis $2 \mathrm{~L} \mathrm{ha}^{-1}$ (Rayati dan Widayat, 1989; 1993; Widayat dan Rayati, 1993).

Aplikasi jamur entomopatogenik di lapangan dipengaruhi oleh banyak faktor, termasuk aplikasi pestisida (Archana dan Ramaswamy, 2012). Aplikasi jamur entomopatogenik dapat dilakukan secara bersamaan dengan pengendalian yang lain seperti penggunaan insektisida yang sesuai jenis dan dosisnya untuk meningkatkan efektivitasnya. Pencampuran keduanya dapat dilakukan dengan metode tank mix dan telah terbukti efektif untuk mengendalikan berbagai jenis hama. Upaya tersebut juga bagian dari manajemen resistensi terhadap hama karena dapat mengurangi aplikasi insektisida sintetik (Ambethgar, 2009). Aplikasi pestisida juga dapat mempengaruhi proses pertumbuhan jamur. Oleh karena itu, perlu diketahui pengaruh pestisida terhadap pertumbuhan jamur entomopatogenik $P$. fumosoroseus.

\section{METODE PENELITIAN}

Penelitian dilaksanakan di Laboratorium Proteksi Tanaman, Pusat Penelitian Teh dan Kina Gambung pada bulan Januari hingga April 2015. Isolat jamur $P$. fumosoroseus diperbanyak menggunakan media Sabouraud Dextrose Yeast Agar (SDYA) dengan ekstrak yeast sebanyak 0,2\% (Gnanaprakasam et al., 2011), diinkubasikan pada suhu $25 \pm 2^{\circ} \mathrm{C}$. Pengujian dirancang dalam Rancangan Acak Lengkap (RAL) dengan 16 perlakuan dan 2 kali ulangan dengan sampel sebanyak 5 buah. Pestisida yang diuji yaitu metomil, bifentrin, imidakloprid, tembaga oksida oksida dan metidation (Tabel 1). Kon-sentrasi masing-masing pestisida yang digunakan merupakan dosis Rekomendasi Lapang (RL), setengah konsentrasi rekomendasi lapang $(0,5 \times \mathrm{RL})$ dan dua kali konsentrasi rekomendasi lapang (2x RL) (Gnanaprakasam et al., 2011).

\section{Uji Vegetatif $\boldsymbol{P}$. fumosoroseus}

Kelima jenis pestisida diuji dengan metode poisoned food technique. Media 
SDYA steril dicampur dengan konsentrasi pestisida yang telah ditentukan dan dituangkan ke dalam cawan petri sebanyak $9 \mathrm{ml}$. Potongan agar dengan miselium $P$. fumosoroseus diletakan dibagian tengah media SDYA yang sudah mengeras. Media tanpa pestisida merupakan perlakuan kontrol (Amutha et al., 2010).

Tabel 1. Konsentrasi pestisida yang di uji

\begin{tabular}{|c|c|c|c|c|c|}
\hline \multirow[t]{2}{*}{ Bahan aktif } & \multirow[t]{2}{*}{ Formulasi } & \multicolumn{3}{|c|}{ Konsentrasi } & Kategori \\
\hline & & $\mathrm{RL}$ & $0.5 \times R L$ & $2 \times R L$ & \\
\hline Metomil & $25 \mathrm{WP}$ & $2,5 \mathrm{~g} \mathrm{~L}^{-1}$ & $1,25 \mathrm{~g} \mathrm{~L}^{-1}$ & $5 \mathrm{~g} \mathrm{~L}^{-1}$ & Insektisida \\
\hline Bifentrin & $25 \mathrm{EC}$ & $2,5 \mathrm{ml} \mathrm{L}^{-1}$ & $1,25 \mathrm{ml} \mathrm{L}^{-1}$ & $5 \mathrm{ml} \mathrm{L}^{-1}$ & Insektisida \\
\hline Imidakloprid & $200 \mathrm{SL}$ & $0,5 \mathrm{ml} \mathrm{L}^{-1}$ & $0,25 \mathrm{ml} \mathrm{L}^{-1}$ & $1 \mathrm{ml} \mathrm{L}^{-1}$ & Insektisida \\
\hline Tembaga oksida & 86 WG & $1 \mathrm{~g} \mathrm{~L}^{-1}$ & $0,5 \mathrm{~g} \mathrm{~L}^{-1}$ & $2 \mathrm{~g} \mathrm{~L}^{-1}$ & Fungisida \\
\hline Metidation & 77 WP & $5 \mathrm{~g} \mathrm{~L}^{-1}$ & $2,5 \mathrm{~g} \mathrm{~L}^{-1}$ & $10 \mathrm{~g} \mathrm{~L}^{-1}$ & Fungisida \\
\hline
\end{tabular}

Semua cawan Petri diinkubasikan pada suhu $25 \pm 2^{\circ} \mathrm{C}$ selama 14 hari. Diameter koloni diukur pada hari ke-14 dan hari ke-30 setelah koloni pada perlakuan kontrol memenuhi cawan Petri. Data yang diperoleh dihitung untuk mendapat persentase penghambatan pertumbuhan $(\mathrm{X})$ dengan rumus sebagai berikut (Amutha et al., 2010):

$$
\mathrm{X}=\frac{\mathrm{Y}-\mathrm{Z}}{\mathrm{Y}} \times 100 \%
$$

$Y$ merupakan diameter koloni kontrol dan Z merupakan diameter koloni yang diberi perlakuan. Hasil yang diperoleh dikategorikan berdasarkan klasifikasi (Amutha et al, 2010) dengan skor uji toksisitas in vitro sebagai berikut: 1 . Tidak toksik (<50\%), 2. Agak Toksik (50-79\%), 3. Toksik (80-90\%), dan 4. Sangat Toksik (>90\%). Setelah 30 hari, untuk mengetahui pengaruh perlakuan terhadap kerapatan spora dihitung dengan cara mengambil 6 koloni $(6 \mathrm{~mm})$ yang dipilih secara acak. Koloni dimasukan ke dalam tabung berisi 10 $\mathrm{ml}$ larutan Tween 20 0,02\% dan dikocok \pm 1 menit. Kerapatan konidia dihitung dengan menggunakan Haemocytometer (Archana dan Ramaswamy, 2012).

\section{Uji Produksi Biomassa}

Uji produksi biomassa dilakukan dengan menggunakan media steril Potato Dextrose Broth (PDB) sebanyak $100 \mathrm{ml}$ dan $1 \mathrm{ml}$ suspensi konidia dengan kerapatan spora 1 x $10^{6}$ spora per $\mathrm{ml}$ untuk masing-masing konsentrasi pestisida. Media diinkubasikan di atas shaker pada suhu $25 \pm 2^{\circ} \mathrm{C}$ selama 10 hari. Pada hari ke-10 media disaring dan dikeringkan pada suhu $80 \pm 1^{\circ} \mathrm{C}$ selama 1 malam untuk memperoleh berat kering kemudian ditimbang (Archana dan Ramaswamy, 2012).

\section{Analisis Statistik}

Data yang diperoleh dianalisis secara statistik dengan one way ANOVA dan diuji lanjut dengan Uji Jarak Berganda Duncan pada taraf $5 \%$ menggunakan software SAS ver.9.1.3.

\section{HASIL DAN PEMBAHASAN}

\section{Hasil Uji Vegetatif}

Hasil analisis pengukuran hari ke-14 menunjukkan bahwa perlakuan imidakloprid pada taraf konsentrasi 0,5x RL berbeda nyata dengan perlakuan lain. Diameter koloni $P$. fumosoroseus pada perlakuan imidakloprid 0,5x RL sebesar 57,5 
$\mathrm{mm}$ dengan persentase peng-hambatan terhadap kontrol kurang dari $10 \%$ yaitu sebesar 0,86\% (Tabel 2). Hasil ini sejalan dengan hasil penelitian Alizadeh et al.
(2007) yang menyatakan bahwa penghambatan pertumbuhan oleh insektisida imidakloprid terhadap jamur Beauveria bassiana juga kurang dari $10 \%$.

Tabel 2. Pengaruh Pestisida Terhadap Pertumbuhan P. fumosoroseus

\begin{tabular}{|c|c|c|c|c|c|}
\hline \multirow[b]{2}{*}{ Perlakuan } & \multicolumn{3}{|c|}{14 Hari setelah inokulasi (HSI) } & \multicolumn{2}{|c|}{$\begin{array}{c}30 \text { Hari setelah inokulasi } \\
\text { (HSI) }\end{array}$} \\
\hline & $\begin{array}{c}\text { Diameter } \\
\text { koloni } \\
(\mathrm{mm})^{*}\end{array}$ & $\begin{array}{c}\text { Persentase } \\
\text { penghambatan } \\
\text { terhadap kontrol } \\
(\%)\end{array}$ & $\begin{array}{l}\text { Tingkat } \\
\text { toksisitas }\end{array}$ & $\begin{array}{c}\text { Diameter } \\
\text { koloni } \\
(\mathrm{mm})^{*}\end{array}$ & $\begin{array}{c}\text { Persentase } \\
\text { penghambat } \\
\text { an terhadap } \\
\text { kontrol (\%) }\end{array}$ \\
\hline Metomil 0,5x RL & $51 \mathrm{abc}$ & 12,07 & 1 & $62,5 \mathrm{ab}$ & 3,85 \\
\hline Metomil RL & $39 \mathrm{bc}$ & 32,76 & 1 & $51,5 \mathrm{abc}$ & 20,77 \\
\hline Metomil 2x RL & $56 a b$ & 3,45 & 1 & $64,0 a b$ & 1,54 \\
\hline Bifentrin $0,5 x \quad R L$ & $45 \mathrm{abc}$ & 22,41 & 1 & $55,0 \mathrm{abc}$ & 15,38 \\
\hline Bifentrin RL & $42 \mathrm{abc}$ & 27,59 & 1 & $51,0 a b$ & 21,54 \\
\hline Bifentrin $2 x \mathrm{RL}$ & 39,5 bc & 31,90 & 1 & $47,0 \mathrm{bc}$ & 27,69 \\
\hline Imidakloprid 0,5x RL & $57,5 \mathrm{a}$ & 0,86 & 1 & $71,5 \mathrm{a}$ & $-9,23$ \\
\hline Imidakloprid RL & $36 \mathrm{c}$ & 37,93 & 1 & $37 \mathrm{c}$ & 43,08 \\
\hline Imidakloprid 2x RL & $46 a b c$ & 20,69 & 1 & $56 \mathrm{abc}$ & 13,85 \\
\hline Tembaga oksida 0,5x RL & $37 \mathrm{c}$ & 36,21 & 1 & $45 \mathrm{bc}$ & 30,77 \\
\hline Tembaga oksida RL & $44,5 \mathrm{abc}$ & 23,28 & 1 & $54,5 \mathrm{abc}$ & 16,15 \\
\hline Tembaga oksida $2 x$ RL & $35,5 c$ & 38,79 & 1 & $37,5 \mathrm{c}$ & 42,31 \\
\hline Metidation $0,5 x \mathrm{RL}$ & $0,9 \mathrm{~d}$ & 100,00 & 4 & $0,9 \mathrm{~d}$ & 100,00 \\
\hline Metidation RL & $0,9 \mathrm{~d}$ & 100,00 & 4 & $0,9 \mathrm{~d}$ & 100,00 \\
\hline Metidation 2x RL & $0,9 \mathrm{~d}$ & 100,00 & 4 & $0,9 \mathrm{~d}$ & 100,00 \\
\hline Kontrol & 58 a & - & - & $65 \mathrm{ab}$ & - \\
\hline
\end{tabular}

*Angka rata-rata yang diikuti huruf yang sama menunjukkan tidak berbeda nyata menurut Uji Jarak Berganda Duncan pada taraf 5\%.

Diameter koloni terkecil ditunjukkan oleh perlakuan imidakloprid RL, tembaga oksida $0,5 \mathrm{x}$ RL dan tembaga oksida $2 \mathrm{x} \mathrm{RL}$ dengan diameter sebesar $36 \mathrm{~mm}, 37 \mathrm{~mm}$, dan 35,5 $\mathrm{mm}$ berturut-turut. Pada pengamatan $30 \mathrm{HSI}$ hasil analisis statistik diameter koloni pada perlakuan imidakloprid 0,5x RL tetap menunjukkan diameter tertinggi bahkan jika dibandingkan dengan kontrol. Diameter koloni pada perlakuan imidakloprid $0,5 \mathrm{x}$ RL sebesar 71,5 mm sedangkan koloni pada kontrol hanya $65 \mathrm{~mm}$. Demikian pula dengan persentase penghambatan, pada perlakuan imidakloprid 0,5x RL $30 \mathrm{HSI}$ sebesar $-9,23 \%$. Dalam hal ini pertumbuhan $P$. fumosoroseus pada perlakuan imidakloprid 0,5x RL lebih tinggi 9,23\% jika dibandingkan dengan kontrol. Hasil penelitian tersebut sesuai dengan yang dilakukan oleh Gnanaprakasam et al., (2011) bahwa insektisida dimethoate mampu meningkatkan pertumbuhan $B$. bassiana pada konsentrasi insektisida sebesar 0,5x RL.

Peningkatan pertumbuhan jamur dan produksi spora dapat meningkat ketika diberi perlakuan insektisida. Hal tersebut dapat terjadi karena respon berbeda yang ditunjukkan oleh mekanisme fisiologis jamur terhadap insektisida. Mekanisme tersebut berkaitan dengan metabolisme tubuh jamur yang mampu memanfaatkan komponen insektisida sebagai sumber nutrisi sekunder. Formulasi bahan aktif insektisida juga dapat secara langsung digunakan sebagai nutrisi untuk meningkatkan pertumbuhan dan produksi spora (Gnanaprakasam et al., 2011). 
Pada seluruh perlakuan konsentrasi metomil, bifentrin, imidakloprid dan tembaga oksida, persentase penghambatan pertumbuhan terhadap $P$. fumosoroseus di bawah $50 \%$ dengan skor uji bernilai 1 . Skor tersebut menunjukkan bahwa pestisida metomil, bifentrin, imidakloprid dan tembaga oksida tidak bersifat toksik terhadap $P$. fumosoroseus. Sedangkan, persentase penghambatan pertumbuhan fungisida metidation terhadap pertumbuhan $P$. fumosoroseus mencapai $100 \%$ baik pada $14 \mathrm{HSI}$ hingga $30 \mathrm{HSI}$. Tingkat toksisitas fungisida metidation mencapai nilai 4 yang berarti fungisida tersebut bersifat sangat toksik terhadap $P$. fumosoroseus.

Persentase penghambatan pertumbuhan terhadap P. fumosoroseus bervariasi pada setiap konsentrasi dan bahan aktif insektisida dan fungisida. Hasil tersebut sesuai dengan hasil penelitian Gnanaprakasam et al. (2011) bahwa persentase penghambatan pertumbuhan dan produksi spora $B$. bassiana sangat bervariasi.

Tabel 3. Persentase produksi spora dan biomasa $P$. fumosoroseus

\begin{tabular}{|c|c|c|c|c|}
\hline Perlakuan & $\begin{array}{l}\text { Kerapatan Spora } \\
30 \mathrm{HSI}\left(\mathrm{X} \times 10^{6}\right)^{*}\end{array}$ & $\begin{array}{c}\text { Persentase Produksi } \\
\text { Spora terhadap kontrol } \\
(\%)\end{array}$ & \multicolumn{2}{|c|}{$\begin{array}{c}\text { Biomassa } 10 \\
\mathrm{HSI}^{(\mathrm{g})}{ }^{*}\end{array}$} \\
\hline Metomil 0,5x RL & $67,25 a b$ & 4,67 & 0,40 & a \\
\hline Metomil RL & $71,15 a b$ & 10,74 & 0,35 & $a b$ \\
\hline Metomil 2x RL & 72,65 a & 13,07 & 0,45 & a \\
\hline Bifentrin $0,5 x \quad R L$ & $6,51 \quad a b$ & 1,40 & 0 & c \\
\hline Bifentrin RL & 73,10 a & 13,77 & 0 & c \\
\hline Bifentrin 2x RL & $71,90 \mathrm{ab}$ & 11,91 & 0 & c \\
\hline Imidakloprid 0,5 x RL & $6,59 a b$ & 2,57 & 0,25 & $b$ \\
\hline Imidakloprid RL & $6,91 a b$ & 7,63 & 0,40 & a \\
\hline Imidakloprid 2x RL & $6,92 a b$ & 7,70 & 0,45 & a \\
\hline Tembaga oksida $0,5 x$ RL & $69,20 a b$ & 7,70 & 0,35 & $a b$ \\
\hline Tembaga oksida RL & $69,90 \mathrm{ab}$ & 8,79 & 0,40 & a \\
\hline Tembaga oksida $2 x$ RL & $7,25 \quad a b$ & 12,84 & 0,35 & $a b$ \\
\hline Metidation $0,5 x \mathrm{RL}$ & $0 \quad c$ & 0 & 0 & c \\
\hline Metidation RL & c & 0 & 0 & c \\
\hline Metidation 2x RL & $0 \quad c$ & 0 & 0 & c \\
\hline Kontrol & $6,42 \quad b$ & - & 0,35 & $a b$ \\
\hline
\end{tabular}

*Angka rata-rata yang diikuti huruf yang sama menunjukkan tidak berbeda nyata menurut Uji Jarak Berganda Duncan pada taraf 5\%.

Hasil uji kerapatan spora (Tabel 3) menunjukkan bahwa kerapatan spora tertinggi ditunjukkan oleh perlakuan metomil 2x RL dan bifentrin RL. Meskipun pada pengujian pertumbuhan perlakuan imidakloprid 0,5x RL menunjukkan diameter paling besar namun tidak sebanding dengan produksi spora yang dihasilkan. Demikian juga dengan bifentrin, meskipun diameter koloni yang terbentuk tidak terlalu besar namun produksi spora yang dihasilkan cukup tinggi yaitu $73,10 \times 10^{6}$ pada konsentrasi sesuai dengan rekomendasi lapang.

Produksi spora, diameter dan tingkat toksisitas yang rendah pada perlakuan bifentrin tidak sebanding dengan produksi biomassa pada media cair PDB. Pada seluruh taraf konsentrasi bifentrin, $P$. fumosoroseus tidak menunjukkan pertumbuhan dan produksi biomassa. Menurut hasil penelitian Hassan dan Charnely dalam Archana dan Ramaswamy (2012) bahwa interaksi yang tidak konsisten antara 
insektisida dan jamur entomopatogenik dapat terjadi. Variasi pertumbuhan dan perkembangan jamur dapat dipengaruhi oleh konsentrasi bahan aktif dan sifat dasar kimia pestisida.

Produksi biomassa pada media PDB berkisar antara 0,25 g hingga 0,45 g. Produksi biomassa terendah ditunjukkan oleh perlakuan imidakloprid 0,5x RL sebesar 0,25 g. Sedangkan, produksi biomassa tertinggi dihasilkan oleh imidakloprid 2x RL sebesar 0,45 g. Hasil tersebut menunjukkan bahwa $P$. fumosorosesus mampu berkembang dengan baik pada berbagai konsentrasi pestisida.

Fungisida metidation menunjukkan konsistensi pada seluruh pengujian, baik pada media SDYA maupun PDB, $P$. fumosoroseus tidak menunjukkan pertumbuhan, produksi spora dan produksi biomassa. Hasil penelitian Gnanaprakasam et al. (2011) menunjukkan bahwa fungisida bordeux dan heksokonazol dapat menghambat germinasi, pertumbuhan vegetatif, dan produksi spora. Demikian pula dengan fungisida triadimefon dapat menghambat produksi spora hingga 99$99,8 \%$.

Mekanisme penghambatan sporulasi dan pertumbuhan vegetatif dapat terjadi dikarenakan bahan aktif pestisida yang mengganggu secara langsung terhadap permeabilitas membran sel, sintesis enzim dan proses metabolisme. Oleh karena itu enzim yang berperan merubah fosfatidiletanalamin menjadi kitin akan terhambat (Archana dan Ramaswamy, 2012).

\section{KESIMPULAN}

Insektisida metomil, imidakloprid dan tembaga oksida kompatibel terhadap pertumbuhan vegetatif dan produksi spora jamur P. fumosoroseus berbagai taraf konsentrasi.

\section{UCAPAN TERIMA KASIH}

Terima kasih kepada Herman bin Lili dan Agus Kurniawan selaku teknisi Proteksi Tanaman Pusat Penelitian Teh dan Kina yang telah membantu selama penelitian berlangsung.

\section{DAFTAR PUSTAKA}

Alizadeh A, Samih MA, Khezri M, Riseh RS. 2007. Compatibility of Beauveria bassiana (Bals.) Vuill. With several pesticides.

(www.ijpaes.com/admin/php/uploads/5 63_pdf.pdf diakses 11 Juni 2014)

Ambethgar, V. 2009. Potential of entomopathogenic fungi in insecticide resistance management (IRM): A review. (http://jbiopest.com/users/LW8/efiles/A mbethgar_V.pdf diakses 21 Oktober 2013).

Amutha, M., J. Gulsar Banu, T. Surulivelu and N. Gopalakrishnan. 2010. Effect of commonly used insecticides on the growth of white Muscardine fungus, Beauveria bassiana under laboratory conditions.

(http://jbiopest.com/users/LW8/efiles/A mutha_M.pdf diakses 21 Oktober 2013)

Archana MR dan Ramaswamy K. 2012. Interactive Effect Of Entomopathogenic Fungi Paecilomyces fumosoroseus With Few Organophosphate And Pyrethroid Pesticides : An In Vitro Study. (http://www.cibtech.org/jls.htm, diakses 21 Mei 2014)

Gnanaprakasam Antony Raj, Sundaram Janarthanan, Stephen D. Samuel, Kathirvelu Baskar dan Savariar Vincent. 
2011.Compatibility of entomopathogenic fungus Beauveria bassiana (Balsamo) Vuillemin isolated from Pulney hills, Western Ghats of Tamil Nadu with insecticides and fungicides.

(http://www.eliirpublisher.com/articles/ 1350647775_40\%20(2011)\%205563-

5567.pdf diakses 21 Oktober 2013).

Islam, M. T. and D. B. Omar. 2012. Combined Effect Of Beauveria bassiana With Neem On Virulence Of Insect In Case Of Two Application Approaches. (http://www.thejaps.org.pk/docs/v-221/29.pdf diakses 21 Oktober 2013)

Lacey, L. A., and M. S. Goettel. 1995. Current Developments In Microbial Control Of Insect Pests And Prospects For The Early 21st Century. (http://link.springer.com/article/10.1007 \%2FBF02372677 diakses 21 Oktober 2013).

Rayati, D.J. dan W. Widayat. 1989. Jamur Patogen Ulat Api (Setora nitens Wlk.), Hama Pada Tanaman Teh. Kongres Nas. dan Seminar Ilmiah PFI. Denpasar: Perhimpunan Fitopatologi Indonesia.
1993. Promising Entomopathogenic Fungi For Biological Control Tea and Cinchona pests; Their Pathogenicity and Some Critical Aspects Of The Disense Induction. Proceding of The Symposium On Integrated Pest Management Control Components. Biotrop Special publ. No. 50. Seameo Biotrop. 8p.

Ross HH, Ross CA, dan Ross JRP. 1982. Entomology. Canada : John Wiley \& Sons.

Sunarno. 2012. Pengendalian Hayati (Biological Control) Sebagai Salah Satu Komponen Pengendalian Hama Terpadu (PHT). (http://journal.uniera.ac.id/abst/31/, diakses 3 Juni 2013).

Widayat, W. dan D. J. Rayati. 1993. Pengaruh Frekuensi Penyemprotan Jamur Entomopatogenik Terhadap Ulat Jengkal (Ectropis bhurmitra) di Perkebunan Teh. Simposium Patologi Serangga I. Yogyakarta: Perhimpunan Entomologi Indonesia. 